\title{
Spatial and Non-Spatial Factors Influencing Willingness to Pay (WTP) for Urban Green Spaces (UGS): A Review
}

\author{
Aimi Norhanani Nordin ${ }^{1}$, Gabriel Hoh Teck Ling ${ }^{1}$, Mou Leong Tan², Chin Siong Ho ${ }^{1}$ \& Hishamuddin Mohd \\ $\mathrm{Ali}^{3}$ \\ ${ }^{1}$ Department of Urban and Regional Planning, Faculty of Built Environment and Surveying, Universiti Teknologi \\ Malaysia, Johor Bahru, Malaysia \\ ${ }^{2}$ Geography Section, School of Humanities, Universiti Sains Malaysia, Penang, Malaysia \\ ${ }^{3}$ Department of Real Estate, Universiti Teknologi Malaysia, Johor Bahru, Malaysia \\ Correspondence: Gabriel Hoh Teck Ling, Department of Urban and Regional Planning, Universiti Teknologi \\ Malaysia, 81300 Johor Bahru, Johor, Malaysia. E-mail: gabriel.ling@utm.my
}

Received: September 15, 2020

doi:10.5539/jsd.v13n6p130
Accepted: October 25, $2020 \quad$ Online Published: November 3, 2020

URL: https://doi.org/10.5539/jsd.v13n6p130

\begin{abstract}
With numerous ecosystem services of urban green spaces (UGS), contributing to sustainability and a better quality of life, UGS provision is perceived as a pivotal role in urban planning. However, concern arises as to what extent local governments have effectively provided good quality and adequate quantity of UGS for the public? Provisioning those UGS aspects has been given a low priority due to insufficient resources and the limited budget allocated by local governments. As such, maintenance and management effectiveness of UGS is detrimentally affected, resulting in disused, overused spaces and thus hot spots for crimes. Therefore, public monetary contribution via taxation is suggested as an alternative to ensuring the continuity and sustainability of UGS services. This review paper is vital to identify and showcase specific factors and mediators, influencing the willingness to pay (WTP) of residents/users for UGS services. Methodologically, after conducting Preferred Reporting Items for Systematic Reviews and Meta-Analyses (PRISMA) for the purpose of article screening and selection based on the two primary databases (Google Scholar and Elsevier), this paper reviewed 18 journal articles, from the year 2013 to 2020. Along with the indirect sub-factors, namely environmental behaviour/attitude and socioeconomic profiles of users, there are three main spatial and non-spatial variables (factors) identified: (i) accessibility/proximity to the nearest UGS; (ii) quantity/adequacy of UGS; and (iii) quality of UGS within a township area, influencing satisfaction and enjoyment as well as reasons and frequency of park visiting of users (mediators), which consequently affect their WTP for UGS.
\end{abstract}

Keywords: mediators, spatial and non-spatial factors, urban green spaces (UGS), willingness to pay (WTP)

\section{Introduction}

Urban green spaces (UGS) have gained a prominent interest in urban planning to deliver a better quality of life. UGS is known as a key indicator of sustainable development, thanks to its tremendous values towards environmental, social, and economic aspects. UGS not only transforms the city's physical dimension (Ebrahimpour et al., 2013), complements the aesthetic (Ahmed et al., 2015), and boosts the property value (Elgizawy, 2014), but it also provides recreational activities, refuge, and retreat for urban dwellers, and promotes social well-being and health (Haq, 2011), as well as fostering relations with natures. Besides, UGS significantly ameliorates air pollution, excessive water runoff, as well as acting a noise barrier and mitigating urban heat island effects (Cilliers \& Timmermans, 2012). However, despite the significant ecosystem services provided by UGS, the protection of UGS has been undervalued by the government due to insufficient resources in terms of budgets and manpower, thus resulting in a lack of UGS maintenance and management. This consequence adversely affects the UGS provision in terms of quantity and quality aspects; overused spaces (e.g., vandalised and misuse space) with no effective management will eventually become underused and disused (Ling, 2019; Ling et al., 2016, 2019). To address the above issues, sufficient public monetary contribution via taxation is suggested as an alternative to ensuring the continuity and sustainability of UGS services. However, concern arises as to what extent users are willing to pay to the local governments for UGS maintenance and management or what specific factors incentivising or disincentivising the public or users to be willing to pay for the services? Drawing on the past literature, it is found 
that there are numerous factors influencing one's intention and willingness to pay for UGS services, which primarily focus on non-spatial factors, such as sociodemographic background of users, preferences and awareness of residents, the quality and management level of UGS. Most of them do not address how spatial factors (location, size, adequacy, types of UGS), determined in the initial stage of space planning and design, impact users' WTP, nor do they explicitly demonstrate and explain how the combination of above factors and other indirect components/factors (mediators) influence the WTP of users, not at least in a conceptually associative fashion. Meaning that, considering the above spatial and non-spatial as well as other sub factors and mediators, most of the studies on WTP for UGS have been conducted in a compartmentalised manner, exploring those factors individually and non-connectedly. Moreover, due to different contextual settings of studies, findings with respect to the effects of the above factors on WTP are varied. Thus, this necessitates further verification and more consistent assertions pertaining to WTP-UGS topics.

Against the above background, this review paper revisited the latest literature by identifying and updating potential factors influencing the willingness to pay (WTP) of users for UGS services. More precisely, this paper developed a conceptual framework (nexus), describing interrelationships between UGS spatial and non-spatial attributes (factors), as well as mediators that encompass users' satisfaction and enjoyment and their reasons and frequency of visiting, with the WTP of users. Not only does this study help bridge the missing gap of previous studies (as a theoretical contribution) on WTP for UGS, this paper also offers insights to policymakers on the importance of taking into account the WTP factors and sub factors towards effectively managing UGS. The remainder of this study continues as follows: (i) the method, covering the PRISMA approach for articles selection and the systematic review; (ii) results and discussions of the findings; and lastly (iii) conclusion and recommendations.

\section{Method}

This study employed a systematic literature review; journal articles were sourced from the two of the largest online databases, such as Elsevier (Science Direct) and Google Scholar. Both review and empirical studies included in the literature review were from the reputable journals, primarily indexed by SCOPUS, and some by Web of Science, namely the International Journal of Business and Society, Urban Forestry \& Urban Greening, Cities, Land Use Policy, the IADIS International Conference on Sustainability, Landscape and Urban Planning, the Journal of Environmental Protection, the International Journal of Management, Knowledge and Learning, Economies, Sustainability, Land, Urban Science, the Journal of Environmental Science International, the American Journal of Engineering Research and Acta Ecologica Sinica.

Specifically, prior to the in-depth review process, the PRISMA method was adopted to carefully and systematically select relevant research from the pool of literature. This method consists of a four-phase flow diagram, which covers identification, screening, eligibility, and inclusion (see Figure 1). Using a Boolean operator 'AND', computerised searches were carried out based on a combination of the following keywords: urban green spaces (UGS), proximity (or other synonymous meanings and terms, such as distance), quality and quantity. For the stage of identification, it started with the year of search, spanning ten years, from 2011 to 2020. The year coverage is relatively recent because this is to highlight the current and updated research findings on the topic.

From the Elsevier database, all records (i.e., papers) identified were 2345, while Google Scholar identified 1999. In total, there were 4344 papers identified based on these two databases. Next, by reviewing each of them manually, all the duplicates of articles were removed. This screening is to avoid reviewing the duplicated articles. Hence, after removing the duplicates, 61 papers were retained. Based on these 61 papers, a screening process by titles and abstracts was undertaken, looking into the suitability and relevancy of the articles. More precisely, indicators to determine the suitability and relevancy of the articles were based on the objective of the study, i.e., focusing on spatial and non-spatial factors, namely proximity or distance, quality and quantity of UGS as well as user's WTP for green spaces. These keywords are also crucial in determining the importance of UGS and user's behaviour/preference towards UGS. Through screening, 26 papers had been excluded, which made the total number of papers for the next phase become 35 .

Next, for the third phase on the eligibility of the screened articles (or "full-text articles assessed for eligibility"), the articles were further assessed based on their full texts and contents. This process, determining whether the articles are truly eligible based on the set criteria and requirements (e.g., geographical/contextual settings and terminology interpretations), thus brought down the total number of papers to 18 . Therefore, for the inclusion phase, the final records (number of papers) included for reviewing purposes were only 18 covering from the year 2013 to 2020 . Note that the year coverage differs from the identification stage above because after the screening and selection process, some papers, which were not fit and relevant to the topic and objectives, published in 2011 and 2012 were excluded. An in-depth review of 18 papers was conducted to answer the research objective, 
specifically concerning user preferences and valuation, user satisfaction on UGS, user motivation of visiting, UGS geographic access and benefits, user's willingness to pay for UGS and socioeconomic status (SES). Further literature also emphasises interrelationships between these attributes that influence the user's willingness to pay (WTP) for UGS maintenance and management.

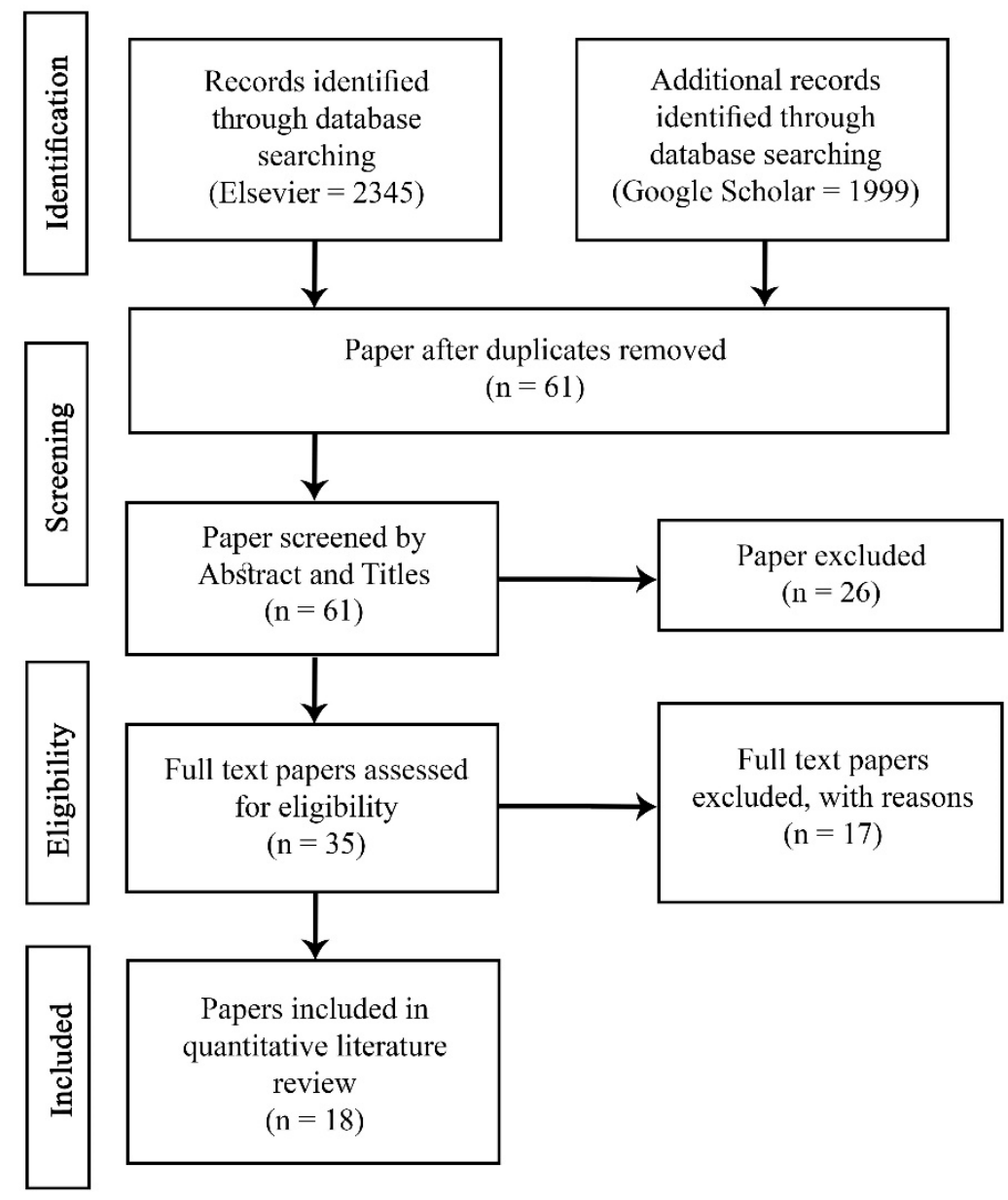

Figure 1. A PRISMA methodology flowchart

Source: UNC Health Science Library. (2020). Creating a PRISMA flow diagram. Retrieved from https://guides.lib.unc.edu/prisma

\section{Results and Discussion}

Although previous studies show varying terminologies for UGS as shown in Table 1, such as urban park (Kim, 2018; Song et al., 2013), urban green area (Forleo et al., 2015) urban nature (Paul \& Nagendra, 2017), urban open spaces (Cook et al., 2018), urban public spaces (Ardeshiri et al., 2018), waterfront open spaces (Dahal et al., 2018), and urban lake recreational area (Othman \& Jafari, 2019), the settings, however, deliver similar descriptions of UGS functions as recreational and retreat areas, ecosystem services providers, and a social place. 
Table 1. Previous studies from 2013-2020

\begin{tabular}{|c|c|c|c|}
\hline Year & Type of Settings & Authors & Research Concern \\
\hline 2013 & Urban park & Song et al., 2013 & $\begin{array}{l}\text { Factors affecting WTP based on frequency, } \\
\text { reasons for visiting and satisfaction }\end{array}$ \\
\hline 2015 & Urban Green Spaces & Zhang et al., 2015 & $\begin{array}{l}\text { Factors affecting residents' satisfaction level } \\
\text { when participating in the Physical Activity (PA) }\end{array}$ \\
\hline 2015 & Urban Green Spaces & Song et al., 2015 & $\begin{array}{l}\text { Assessing the relationship between motivation } \\
\text { and WTP for UGS conversation }\end{array}$ \\
\hline 2015 & Urban Green Area & Forleo et al., 2015 & $\begin{array}{c}\text { Factors affecting young people WTP for } \\
\text { conservation }\end{array}$ \\
\hline 2016 & Urban Green Spaces & Akpinar, 2016 & $\begin{array}{l}\text { The association between quality of UGS, self- } \\
\text { reported physical activity (PA) and health } \\
\text { indicators }\end{array}$ \\
\hline 2017 & Urban Nature & Paul \& Nagendra, 2017 & $\begin{array}{c}\text { The uses and perception of different population } \\
\text { groups (quality of nature, distance to green } \\
\text { spaces and frequency of uses) }\end{array}$ \\
\hline 2018 & Urban Open Spaces & Cook et al., 2018 & $\begin{array}{l}\text { Focusing on eliciting WTP estimate for its } \\
\text { preservation via taxation. }\end{array}$ \\
\hline 2018 & Urban Green Spaces & $\begin{array}{c}\text { Biernacka \& } \\
\text { Kronenberg } 2018\end{array}$ & $\begin{array}{l}\text { Identifying and classifying institutional barriers } \\
\text { which prevent the use of urban green spaces } \\
\text { (UGS) }\end{array}$ \\
\hline 2018 & Urban Park & Kim \& Jin 2018 & $\begin{array}{l}\text { Relationships between individual subjective } \\
\text { well-being and urban park }\end{array}$ \\
\hline 2018 & Urban Public Spaces & Ardeshiri et al., 2018 & $\begin{array}{c}\text { Residents' preference and valuation of living } \\
\text { proximity to urban amenities in a built } \\
\text { environment }\end{array}$ \\
\hline 2018 & Urban Green Spaces & Rigolon et al., 2018 & $\begin{array}{l}\text { Measuring the access to UGS based on SES and } \\
\text { race ethnicity in Global South Cities }\end{array}$ \\
\hline 2018 & Urban Green Spaces & Aziz et al., 2018 & $\begin{array}{l}\text { Evaluating visitors' preference and uses of green } \\
\text { spaces regarding frequency, type of uses, visiting } \\
\text { time and duration of visit }\end{array}$ \\
\hline 2018 & Urban Green Spaces & Madureira, 2018 & $\begin{array}{c}\text { Examining UGS preference characteristics based } \\
\text { on quality, quantity, satisfaction, frequency of } \\
\text { visiting) }\end{array}$ \\
\hline 2018 & Urban Green Spaces & Nath et al., 2018 & $\begin{array}{c}\text { Assessing park users' characteristics, quality of } \\
\text { park and users' willingness to contribute towards } \\
\text { park management }\end{array}$ \\
\hline 2018 & $\begin{array}{l}\text { Waterfront Open } \\
\text { Spaces }\end{array}$ & Dahal et al., 2018 & $\begin{array}{c}\text { Estimating residents' willingness to pay (WTP) } \\
\text { to preserve open space in coastal cities } \\
\text { (conservation organisation, income, age, the } \\
\text { residence of duration) }\end{array}$ \\
\hline 2019 & Urban Green Spaces & Gozalo et al., 2019 & $\begin{array}{l}\text { Examining the relationship between citizens' } \\
\text { perception of park features and their uses as a } \\
\text { function of the size }\end{array}$ \\
\hline 2019 & $\begin{array}{c}\text { Urban Lake } \\
\text { Recreational Park }\end{array}$ & Othman \& Jafari, 2019 & $\begin{array}{l}\text { Estimating economic benefits of recreational } \\
\text { experiences to identify efficient entrance fees to } \\
\text { the park }\end{array}$ \\
\hline 2020 & Urban Green Spaces & Sabyrbekov et al., 2020 & $\begin{array}{l}\text { Measuring WTP for public UGS based on } \\
\text { environmental, economic and nature relatedness } \\
\text { as non-monetary valuation }\end{array}$ \\
\hline
\end{tabular}


From this review, generally, there are three key factors (variables/attributes): proximity, quality, and quantity of urban green spaces (UGS). These variables affect the level of user satisfaction and enjoyment (Sabyrbekov et al., 2020), as well as the reason of visiting and frequency of visiting UGS which hence influence users' decision as to whether to contribute or pay for the services. Environmental behaviour and attitude, affected by the proximity of UGS from their house, also influences users' awareness towards WTP and thus the maintenance and management of UGS. Meanwhile, WTP for UGS services is also determined by some trivial attributes of users' socioeconomic profiles, such as occupation, income, and education.

According to Rigolon et al., (2018), the above main variables, primarily based on the geographic access to urban green spaces (UGS) (Aziz et al., 2018; Madureira et al., 2018), influence users' preferences. The spatial and nonspatial attributes/variables are further summarised as follows: (i) proximity - The distance of the nearest green spaces to their houses or within the township area will affect the accessibility and frequency of visiting. However, it does not take account for the numbers of green spaces, size, amenities, maintenance, and safety; (ii) quality considering the conditions of amenities, maintenance level, and safety of green spaces for access and consumption purposes. These are also included as part of environmental quality, such as controlling noise pollution and air quality (Sabyrbekov et al., 2020) and serving as an aesthetic value through landscaping; and lastly (iii) quantity The size, numbers, and availability of green spaces that can be accessed and consumed. The size and design layout of UGS will also influence the arrangement of spaces and activities. However, it does not take into account amenities, maintenance, and safety purposes. Therefore, it is crucial to consider all three variables (factors) simultaneously to obtain a holistic view.

The present study provides three main findings. First, how spatial and non-spatial factors, namely proximity, quality, and quantity of UGS could affect users' satisfaction and enjoyment in using the green space. Proximity and quantity of UGS are grouped as spatial factors, apart from the quality of UGS, a non-spatial factor, that directly affects user's satisfaction and enjoyment, and thus WTP for UGS. These three main factors show strong associations with WTP for UGS. Meanwhile, relative to the main factors, other non-spatial factors involving environmental behaviour and attitudes as well as socioeconomic profiles show indirect and less significant (weak) associations with close proximity to UGS, reason and frequency of visiting as well as WTP for UGS. Given the weak and indirect relationships, they could be due to different users' perspectives towards the importance of UGS. Second, how the previous finding (users' satisfaction and enjoyment) is associated with their reasons and frequency of visiting UGS (mediators), which then contribute to users' willingness to pay (WTP) for UGS services. Lastly, a conceptual framework (see Figure 2) was developed to illustrate interrelationships between spatial and non-spatial factors which influence WTP of users for UGS services.

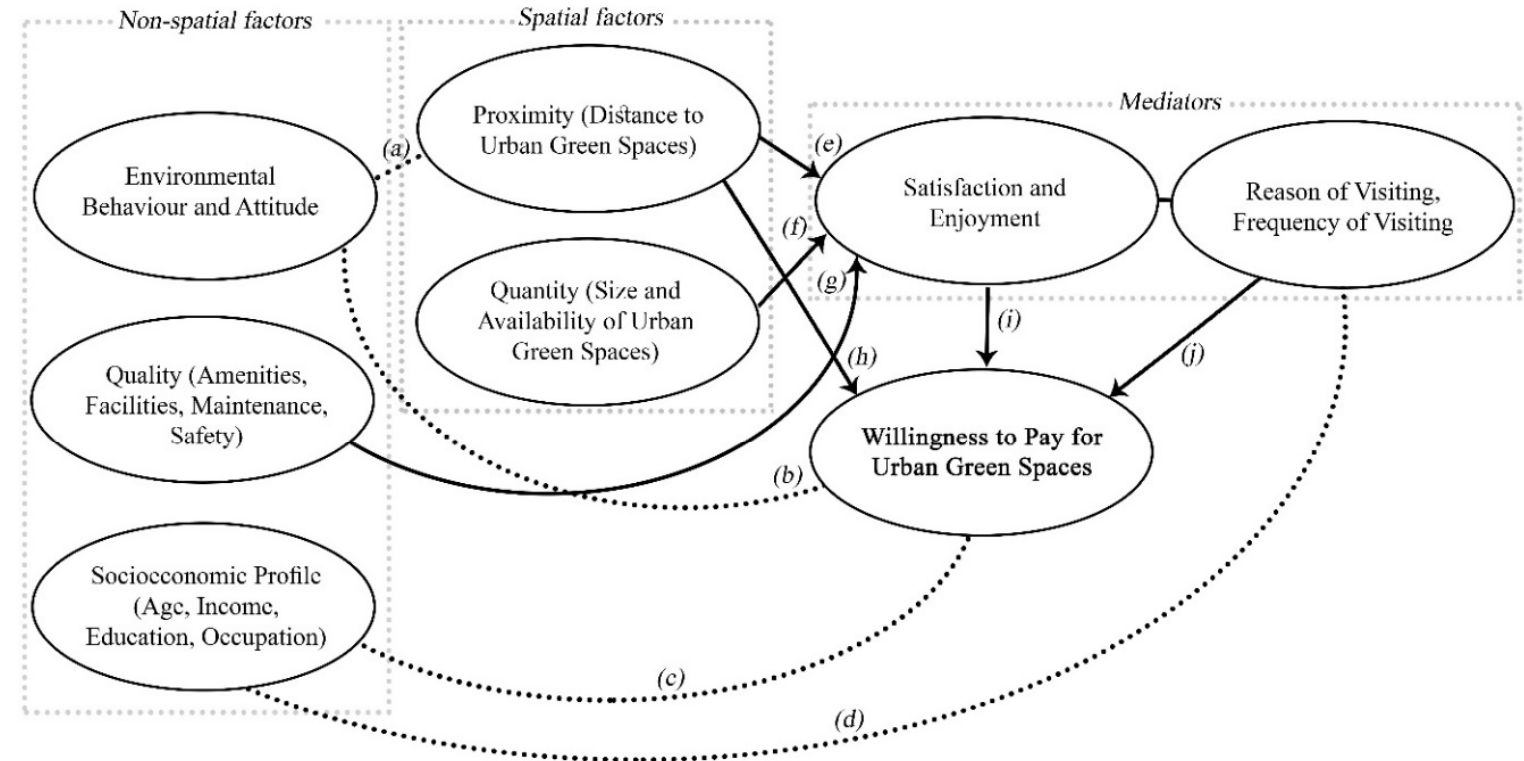

(a) (b) (c) $(d)=$ weak and indirect link $(\mathrm{e})(\mathrm{f})(\mathrm{g})(\mathrm{h})=$ strong and direct link

(i) $(i)=$ strong and direct link (mediators)

Figure 2. A conceptual framework illustrating interrelationships between variables influencing willingness to pay (WTP) for urban green spaces (UGS) services 
It is found that the proximity and quality of urban green spaces (UGS) are among the primary factors determining users' satisfaction and enjoyment when accessing green spaces. The shorter the distance to the nearest UGS in a township area, the better it is because this allows easy access which increases users' frequency to use the available green spaces. This also positively contributes to the users' WTP for the services (Sabyrbekov et al., 2020). According to Dahal et al., (2018), users who reside close to open spaces are willing to pay more for its preservation. This indicates that living near the green area or natural environment will improve users' environmental behaviour and attitude, which then increase their awareness and concern towards the UGS maintenance and management. Such an environmental behaviour, e.g., visiting natural areas, signifies the existence of a green attitude (Forleo et al., 2015). However, higher nature attachment does not necessarily lead to higher WTP due to socioeconomic constraints, such as income, education, and household size (Sabyrbekov et al., 2020). Therefore, this study concludes that close proximity or distance to the nearest urban green spaces (UGS) significantly corresponds to the frequency of visiting, consequently contributing to the satisfaction and enjoyment of park users.

Furthermore, users will be more satisfied when urban green spaces (UGS) are well maintained (Akipinar, 2016), clean, with good air quality and without noise pollution (Gozalo et al., 2019). Lack of fitness equipment and poor maintenance of vegetation are among the reasons that contribute to decreasing levels of satisfaction (Zhang et al., 2015). Besides, safety also plays an essential role in determining the quality of urban green spaces (UGS) because women are less likely to use the green spaces compared to men if they feel insecure and not safe (Rigolon et al., 2019). This safety consideration also confirms the study by Paul \& Nagendra (2017), in which, compared to male users, only female users considered the overall quality of spaces inadequate and poor once they do not feel safe at the space. Hence, this safety reason most likely reduces the frequency of visiting UGS. As a result, this study indicates that the quality of urban green spaces (UGS) positively correlates with the level of satisfaction and enjoyment, which eventually affects the reason and frequency of visits. This is supported by Paul \& Nagendra (2017) because users are more willing to travel more than $10 \mathrm{~km}$ from home to another park that is larger, well maintained, and attractive. Similar preference is found in a study conducted in Portuguese cities emphasising their satisfaction of quality and quantity of UGS (Madureira et al., 2018). This indicates that both quality and quantity attributes of UGS significantly influence the reasons and frequency of visiting.

This study further discusses how the quantity of urban green spaces (UGS), such as the size and adequacy/availability of spaces in the township area act as the third factor. Larger UGS usually can accommodate various activities (more attractive and choices) for users, thus increasing users' reasons and frequency of visiting. Moreover, the presence of larger UGS is likely to offer more appealing and attractive designs with good layout and distribution not only for facilities and amenities allocation but also vegetation and landscaping. This increases users' satisfaction through functional spaces and aesthetic values. The attractiveness of UGS also corresponds to users' need, expectation, and preference; with bigger and more attractive spaces, they justify users' reasons for visiting and encourage them to have a longer duration of staying and spending time (Biernacka \& Kronenberg, 2018). However, interestingly, the larger size of UGS appearing to attract more people to come because of its multipurpose function may somehow cause users' dissatisfaction due to negative externalities, i.e., overcrowding (Othman \& Jafari, 2019) and noise issues produced by human activities (Nath et al., 2018). According to Zhang et al., (2015), the size of green spaces should be considered along with the distance to reach it, as smaller green spaces will become one of the reasons for seldom use and visiting. However, they also addressed that users' satisfaction will improve, regardless of the size if there are actions taken to tackle the issues. Hence, despite the size of UGS, this study also reveals the importance of availability and adequacy of UGS; so long as there is UGS which can be equally accessible and considerably adequate for users to perform their activities, it satisfies users.

Besides, reasons of visiting UGS are also influenced by other spatial attributes of UGS, for example whether spaces can cater for physical activities (Zhang et al., 2015), passive activities, such as reading, taking children outside, relaxing, walking and talking and others activities, e.g., social gathering. A previous study reported a strong association between UGS and a healthy lifestyle. Moreover, by understanding the reasons of (not) visiting, it shapes future park design and management, and questions on how different groups of people perceive the importance of UGS can also be explored. However, some studies also show that the frequency of visiting UGS is inversely associated with reasons for visiting (Madureira et al., 2018). For examples, due to different occupational groups, such as professionals, retired residents, and students, they appear to have different commitments and preferred activities; therefore, time and duration invested at UGS vary individually. Therefore, generally, good reasons for visiting may increase users' frequency of visiting UGS, but it still depends on individuals themselves.

Based on the above associations, users' WTP can be deduced. Willingness to pay (WTP) for UGS preservation appears to be significantly associated with users who live within the proximity of the park (Cook et al., 2018), and to spare users' leisure time, older people are more willing or tend to pay more for better access to the park 
(Ardeshiri et al., 2018). An addition to the previous finding, it is also shown that individuals may refuse to pay due to the bad quality of UGS such as lack of maintenance for facilities and amenities creating inconveniences which eventually ensue in users' dissatisfaction (Song et al., 2013). However, users are still willing to reconsider their not-to-pay decision if the relevant authority takes necessary steps to improve UGS conditions. Moreover, previous studies also argued that UGS services should not be paid by the public (users/residents) because they believed such public goods should be entirely held responsible, and financially supported, by the government (Othman \& Jafari, 2019), and some other reasons that affect users' decision and their WTP, include their concern as to whether the money paid will be embezzled (Forleo et al., 2015). Also, due to specific reasons, there are issues where some individuals are still required to contribute, although they may not be using or enjoying any green spaces. This consequently makes those individuals less willing to pay for UGS services.

Socioeconomic profiles, such as income group, education group, and occupation group, are another attribute that may not significantly affect users' WTP for UGS services. The higher household income (Kim \& Jin, 2018) and the higher education level, leading to a higher frequency of visits and satisfaction, are positively associated with WTP (Sabyrbekov et al., 2020). This is contrary to the low-income groups and students who may refuse or not willing to pay for UGS services due to the financial constraint. However, the previous findings on the effects of education and income groups on WTP vary. For example, according to Nath et al., (2018), there is a positive result that users are willing to contribute to park management funds in order to improve the management and maintenance of the park, despite individuals' socioeconomic status.

\section{Conclusion and Recommendations}

In the light of the current management and quality issues of UGS, and seeing the importance of UGS protection and management via continuous and sustainable monetary contribution from the public, this study, through a review of the 18 articles using PRISMA, explored what and how spatial and non-spatial variables, which can be deemed as primary and sub factors, influence willingness to pay (WTP) for urban green spaces (UGS) services. Via the understanding of the mediating factors, covering the reasons and frequency of visiting as well as the level of satisfaction and enjoyment when accessing UGS, three main spatial and non-spatial variables/attributes (proximity/location, quality, and quantity) of UGS were found significant in determining and influencing users' WTP for UGS services. Along with the main variables, this study also shows that individuals' subjective factors (e.g., socioeconomic background and environmental behaviours) play a minor role in determining users' WTP. In other words, through a provision of good quality and adequate UGS, coupled with close proximity within a township area, they will lead to higher satisfaction and enjoyment of users and therefore increase their WTP for UGS services provided. However, to effectively maintain the quality of spaces, it requires collective action/efforts where both governments and the public should play their roles. The government should provide better quality and an adequate number of UGS with close proximity (e.g., within walking distance, 400-500m), whereas the public should use the provided amenities and facilities responsibly and courteously. Therefore, this study offers a few takeaways to policymakers (local governments) that when designing and improving the provision of urban green spaces, the above variables should be taken into account since they influence users' preferences, consumption pattern and maintenance intention towards UGS (Ling et al., 2016; Ling, 2019) as well as their satisfaction and enjoyment, which consequently affect their WTP for UGS services. Despite the findings above, the study has limitations. Currently, the findings on the associations between factors, mediators, and WTP have been derived qualitatively (subjectively) or in a relative manner based on the number of articles selected; albeit this sufficiently provides general, overall associations on how and which spatial and non-spatial factors influence or are more significantly associated with WTP, questions regarding to what degree, in a more quantitative fashion, if not statistically, are those factors significantly associated with or explaining WTP likelihood, are yet to be addressed. Other potential variables or components, namely demographic and institutional factors should also be studied and included as part of the existing spatial and non-spatial factors in order to formulate a more holistic framework. Lastly, to further validate and substantiate the conceptual framework and its interrelationships, this study suggests that more empirical quantitative research should be carried out.

\section{Acknowledgments}

This work was financially supported by the Ministry of Education Malaysia and Universiti Teknologi Malaysia through the Research University Grant (GUP) Q.J130000.2652.16J54.

\section{References}

Abdul Aziz, N. A., van den Bosch, K., \& Nillson, K. (2018). Recreational use of urban green space in Malaysian cities. International Journal of Business and Society, 19(S1), 1-16.

Ahmed, M. R., Hassan, R., Beach, P. S., Park, D. C. H., Hill, C., Park, S. A., \& Park, S. (2015). People 'S 
Perception Toward Value of Urban Greenspace in Environmental Development. Bernatzky 1978, 1-7.

Akpinar, A. (2016). Urban Forestry \& Urban Greening How is quality of urban green spaces associated with physical activity and health? Urban Forestry \& Urban Greening, 16, 76-83. https://doi.org/10.1016/j.ufug.2016.01.011

Ardeshiri, A., Willis, K., \& Ardeshiri, M. (2018). Exploring preference homogeneity and heterogeneity for proximity to urban public services. Cities, 81(May), 190-202. https://doi.org/10.1016/j.cities.2018.04.008

Biernacka, M., \& Kronenberg, J. (2018). Urban Forestry \& Urban Greening Classification of institutional barriers affecting the availability, accessibility and attractiveness of urban green spaces. Urban Forestry \& Urban Greening, 36(May), 22-33. https://doi.org/10.1016/j.ufug.2018.09.007

Cilliers, E. J., \& Timmermans, W. (2012). Planning for Sustainable Green Spaces in Developing Countries: Linking Economic Value to Green. IADIS International Conference on Sustainability, Technology and Education, September 2017, 77-84. Retrieved from https://www.researchgate.net/publication/319553318_PLANNING_FOR_SUSTAINABLE_GREEN_SPAC ES_IN_DEVELOPING_COUNTRIES_LINKING_ECONOMIC_VALUE_TO_GREEN

Dahal, R. P., Grala, R. K., Gordon, J. S., Petrolia, D. R., \& Munn, I. A. (2018). Land Use Policy Estimating the willingness to pay to preserve waterfront open spaces using contingent valuation, 78(June), 614-626. https://doi.org/10.1016/j.landusepol.2018.07.027

Davíðsd, B., Cook, D., \& Eiríksd, K. (2018). $€$ rk, Iceland e Willingness to The contingent valuation study of Heiðm o pay for its preservation, 209, 126-138. https://doi.org/10.1016/j.jenvman.2017.12.045

Ebrahimpour, M., Saremi, H. R., \& Khakpour, B. (2013). Analyzing of urban green spaces development process with emphasis on sustainable principles (Case study: Mashhad metropolitan). American Journal of Engineering Research, 2(4), 113-119. Retrieved from https://profdoc.um.ac.ir/paper-abstract-1054839.html

Elgizawy, E. M. (2014). The significance of urban green areas for the Sustainable community. Egypt by Al-Azhar Engineering-Thirteenth International Conference-2014. Arch. Amira Mostafa, 1(December 2014), 0.

Forleo, M. B., Gagliardi, N., \& Romagnoli, L. (2015). Determinants of Willingness to Pay for an Urban Green Area: A Contingent Valuation Survey of College Students. International Journal of Management, Knowledge and Learning, 4(1), 7-25.

Gozalo, G. R., Miguel, J., Morillas, B., \& González, D. M. (2019). Urban Forestry \& Urban Greening Perceptions and use of urban green spaces on the basis of size. Urban Forestry \& Urban Greening, 46(May), 126470. https://doi.org/10.1016/j.ufug.2019.126470

Haq, S. M. A. (2011). Urban Green Spaces and an Integrative Approach to Sustainable Environment. Journal of Environmental Protection, 02(05), 601-608. https://doi.org/10.4236/jep.2011.25069

Kim, D., \& Jin, J. (2018). Does happiness data say urban parks are worth it? Landscape and Urban Planning, 178(October 2017), 1-11. https://doi.org/10.1016/j.landurbplan.2018.05.010

Ling, G. H. T. (2019). Ostrom's Collective-Action in Neighbourhood Public Open Space: Evidence from Sabah, Malaysia. Institutions and Economies, 11(4), 103-134.

Ling, G. H. T., Leng, P. C., \& Ho, C. S. (2019). Effects of diverse property rights on rural neighbourhood public open space (POS) governance: Evidence from Sabah, Malaysia. Economies, 7(2). https://doi.org/10.3390/economies7020061

Ling, G. H. T., Siong, H. C., Mohd, A. H., \& Fan, T. (2016). Do institutions matter in neighbourhood commons governance? A two-stage relationship between diverse property-rights structure and residential public open space (POS) quality: Kota Kinabalu and Penampang, Sabah, Malaysia. International Journal of the Commons, 10(1), 294-333. https://doi.org/10.18352/ijc.618

Madureira, H. (2018). Preferences for Urban Green Space Characteristics: A Comparative Study in Three Portuguese Cities. https://doi.org/10.3390/environments5020023

Nath, T. K., Sim, S., Han, Z., \& Lechner, A. M. (2018). Urban Forestry \& Urban Greening Urban green space and well-being in Kuala Lumpur, Malaysia. Urban Forestry \& Urban Greening, 36(February), 34-41. https://doi.org/10.1016/j.ufug.2018.09.013

Othman, J., \& Jafari, Y. (2019). Economic valuation of an urban lake recreational park: Case of Taman Tasik Cempaka in Bandar Baru Bangi, Malaysia. Sustainability (Switzerland), 11(11). 
https://doi.org/10.3390/su11113023

Paul, S., \& Nagendra, H. (2017). Factors Influencing Perceptions and Use of Urban Nature: Surveys of Park Visitors in Delhi. https://doi.org/10.3390/land6020027

Rigolon, A., Browning, M., Lee, K., \& Shin, S. (2018). Access to Urban Green Space in Cities of the Global South: A Systematic Literature Review. Urban Science, 2(3), 67. https://doi.org/10.3390/urbansci2030067

Sabyrbekov, R., Dallimer, M., \& Navrud, S. (2020). Nature affinity and willingness to pay for urban green spaces in a developing country. Landscape and Urban Planning, 194(December 2018), 103700. https://doi.org/10.1016/j.landurbplan.2019.103700

Song, X.-H., Cho, T.-D., Lang, X.-X., \& Piao, Y.-J. (2013). Influencing the Willingness to Pay for Urban Park Service Functions. Journal of Environmental Science International, 22(10), 1279-1285. https://doi.org/10.5322/JESI.2013.22.10.1279

Song, X., Lv, X., \& Li, C. (2015). Acta Ecologica Sinica Willingness and motivation of residents to pay for conservation of urban green spaces in Jinan, China. CHNAES, 35(4), 89-94. https://doi.org/10.1016/j.chnaes.2015.06.003

Zhang, W., Yang, J., Ma, L., \& Huang, C. (2015). Urban Forestry \& Urban Greening Factors affecting the use of urban green spaces for physical activities: Views of young urban residents in Beijing. Urban Forestry \& Urban Greening, 14(4), 851-857. https://doi.org/10.1016/j.ufug.2015.08.006

\section{Copyrights}

Copyright for this article is retained by the author(s), with first publication rights granted to the journal.

This is an open-access article distributed under the terms and conditions of the Creative Commons Attribution license (http://creativecommons.org/licenses/by/4.0/). 